\title{
A aplicação de parâmetros morfométricos no estudo do relevo das bacias do Rio Santo Antônio e Ribeirão Grande, Serra da Canastra, Sudoeste de Minas Gerais
}

\author{
The application of morphometric parameters in the relief study of the Santo Antonio and \\ Ribeirão Grande river basins, Canastra Range, Southwest Minas Gerais
}

Camila Silva Magalhães

Geógrafa, Mestre em Geografia camillasmagalhaes@yahoo.com.br

\author{
Silvio Carlos Rodrigues \\ Geógrafo, Professor Titular, Instituto de Geografia - UFU \\ silgel@ufu.br
}

\begin{abstract}
Resumo
O presente trabalho tem como objetivo estudar como se configura a morfodinâmica das áreas compreendidas pelas bacias do Rio Santo Antônio e do Ribeirão Grande, localizadas na região sudoeste de Minas Gerais, utilizando-se de análises geomorfométricas, auxiliadas pelo uso de geotecnologias. Para isso, através da base cartográfica disponibilizada pelo IBGE em escala 1:50.000 da área de estudo, foi gerado um modelo digital de terreno hidrologicamente consistido (MDT-HC), a partir do qual foram extraídos e mensurados os atributos a serem correlacionados nos parâmetros morfométricos, buscando elucidar os aspectos lineares, areais e hipsométricos dessas bacias. Além disso, frente ao seu complexo contexto geotectônico, oriundo da evolução diacrônica da Faixa Brasília Meridional, também foi elaborado um mapa de lineamentos identificando feições morfoestruturais e morfológicas lineares de maior detalhe para essa área. Por fim, nos resultados, busca-se espacializar e ilustrar as relações entre a morfometria e a morfologia da região estudada, comprovando-se a profunda influência dos aspectos geotectônicos sobre essas e que, apesar das várias semelhanças aparentes, elas possuem dinâmicas energéticas diferenciadas.
\end{abstract}

Palavras-chave: Geomorfologia; Geomorfometria; Morfoestruturas; MDT hidrologicamente consistente.

\begin{abstract}
This work aimed to study the morphodynamics of areas that encompass the Rio Santo Antonio and Ribeirão Grande basins, located in the southwestern region of Minas Gerais, by using geomorphometric analysis aided by geotechnology. For such, it was generated a hydrologicallycorrect digital surface model through a cartographic base in a 1: 50,000 scale provided by IBGE, from which the attributes correlated in the morphometric parameters were extracted and measured, seeking to clarify the linear, areas and hypsometric aspects of these basins. Moreover, front to the complex geotectonic context derived from the diachronic evolution of the southern Brasilia Belt, it was also produced in detail a lineaments map, identifying linear morphostructural and morphological features. Thus, the results sought to spatialise and to illustrate the relationship between the morphometry and the morphology of the study area, confirming the strong influence of geotectonic aspects on these locations, and that despite the several apparent similarities they have different dynamic energy.
\end{abstract}

Keywords: Geomorphology; Geomorphometry; Morphostructures; Hydrologically Correct DEM. 


\section{INTRODUÇÃO}

Segundo Christofoletti (1980), os cursos de água se configuram como um dos agentes de processo morfogenético mais ativos na esculturação das paisagens terrestres, de forma que através da análise da rede hidrográfica, numerosas questões geomorfológicas podem ser esclarecidas. Assim sendo, compreende-se a análise morfométrica de bacias hidrográficas como uma análise quantitativa, considerando sua expressão e configuração espacial, dos elementos do modelado terrestre, ou seja, o conjunto das vertentes e canais que compõem o relevo, sendo os valores medidos correspondentes aos atributos desses elementos (CHRISTOFOLETTI, 1999).

Além dos subsídios, que sua arquitetura e geometria podem oferecer ao entendimento da evolução geomorfológica de determinada área, a análise morfométrica de bacias hidrográficas, também pode colaborar na assimilação e influência dos seus aspectos morfoestruturais (passivos) e/ou morfotectônicos (ativos), visto que, a rede de drenagem se configura como o elemento mais sensível à ocorrência de alterações crustais (COUTO, 2011).

E com surgimento dos Sistemas de Informação Geográfica (SIGs) em meados da década de 1960 e a incorporação das tecnologias informacionais e computacionais na automação da análise e modelagem de sistemas ambientais; a aquisição, o armazenamento, a manipulação, a interpretação e a apresentação dos dados que antes demandavam dispendiosas jornadas de trabalho, passa a obter maior rapidez na execução das atividades, melhor consistência na execução de cálculos diversos, aumento de precisão e acurácia à técnica, maior uniformidade nos procedimentos operacionais e, no seu conjunto, maior integração entre as diferentes etapas da atividade cartográfica (MATIAS, 2001).

Neste contexto, observa-se que a região ao sul da Serra da Canastra, com exceção dos variados trabalhos que discorrem sobre o contexto geológico regional e local da área de abrangência das bacias a serem analisadas, carece de estudos sistemáticos em escala de detalhe que abordem tanto seus componentes bióticos quanto abióticos, dentre os quais destacamos seus atributos geomorfológicos.

Partindo da perspectiva de se trabalhar com a análise morfométrica de bacias hidrográficas para a caracterização evolucional do relevo, a escolha da área de estudo da presente pesquisa se orientou na busca por bacias que apresentassem visualmente, num primeiro momento, comportamentos morfodinâmicos diferenciados de seu entorno, destacando-se assim, as bacias do Rio Santo Antônio e do Ribeirão Grande, situadas no conjunto do Chapadão da Babilônia, região sudoeste de Minas Gerais.

Estas, apresentam tendências e padrões de drenagem fortemente controlados pela estrutura geológica da região em que se encontram, tendo seus cursos d'água principais, em sua maior parte, 
organizados paralelamente à direção geral NW-SE das camadas litológicas, enquanto seus tributários de menor ordem hierárquica ocupam as direções, preferencialmente, NE-SW dos alinhamentos coincidentes às juntas. Tal organização e configuração espacial dessas bacias de drenagem, em sua análise sobre uma imagem de satélite ou carta topográficas, por exemplo, podem confundir observadores desatentos, fazendo-lhes considera-las como uma única bacia, o que é explicado pelo tênue divisor topográficos que as separa em sua área limítrofe, onde algumas de suas nascentes apresentam distâncias aproximadas a $150 \mathrm{~m}$.

Além disso, estas duas bacias abrangem grande parte da área reintegrada - ainda não regularizada - aos limites do Parque Nacional da Serra da Canastra durante o processo de elaboração do seu novo plano de manejo entre 2001 e 2005, caracterizando-se como uma região com vários conflitos de posses da terra e de interesses econômicos distintos, orientados, por exemplo, pela presença de reserva diamantífera com grande potencial de aproveitamento econômico imediato e pelo turismo calcado na geodiversidade característica da região da Serra da Canastra. $\mathrm{O}$ que torna os estudos desenvolvidos aqui, possíveis fontes de subsídio para ações de ordenamento e gestão territorial nesta área.

Diante do exposto, o presente estudo tem como objetivo geral verificar como se configura a dinâmica interna e, consequentemente, a evolução do relevo nas áreas compreendidas pelas bacias do Rio Santo Antônio e Ribeirão Grande, por meio da sua análise morfológica e morfométrica, auxiliada pelo uso de Sistema de Informação Geográficas, sendo gerado um modelo numérico de terreno consistente à escala de análise e aos aspectos hidrológicos das áreas de pesquisa, a partir do qual foram construídos e comparados os parâmetros geomorfométricos que auxiliaram no entendimento da dinâmica interna das bacias e, consequentemente, na evolução do seu relevo. Neste sentido, foi identificada a existência de anomalias na rede de drenagem por meio das análises geomorfométricas, como a Relação Declividade Extensão (RDE) para as quais se buscou entender possíveis influências morfoestruturais e morfotectônicas em suas configurações.

\section{LOCALIZAÇÃO DA ÁREA DE ESTUDO}

Localizadas entre as latitudes de $20^{\circ} 08^{\prime}$ e $20^{\circ} 34^{\prime}$ sul e as longitudes de $46^{\circ} 22^{\prime}$ e $46^{\circ} 56^{\prime}$ oeste, as bacias hidrográficas do Rio Santo Antônio e do Ribeirão Grande abrangem parte do território de três municípios situados na porção sudoeste do estado de Minas Gerais: Delfinópolis, São João Batista da Glória e São Roque de Minas. Sendo que dos quase $890 \mathrm{~km} 2$ que elas perfazem, aproximadamente $89 \%$ desta área se encontra dentro dos limites do reconhecido Parque Nacional da Serra da Canastra (Figura 1). 

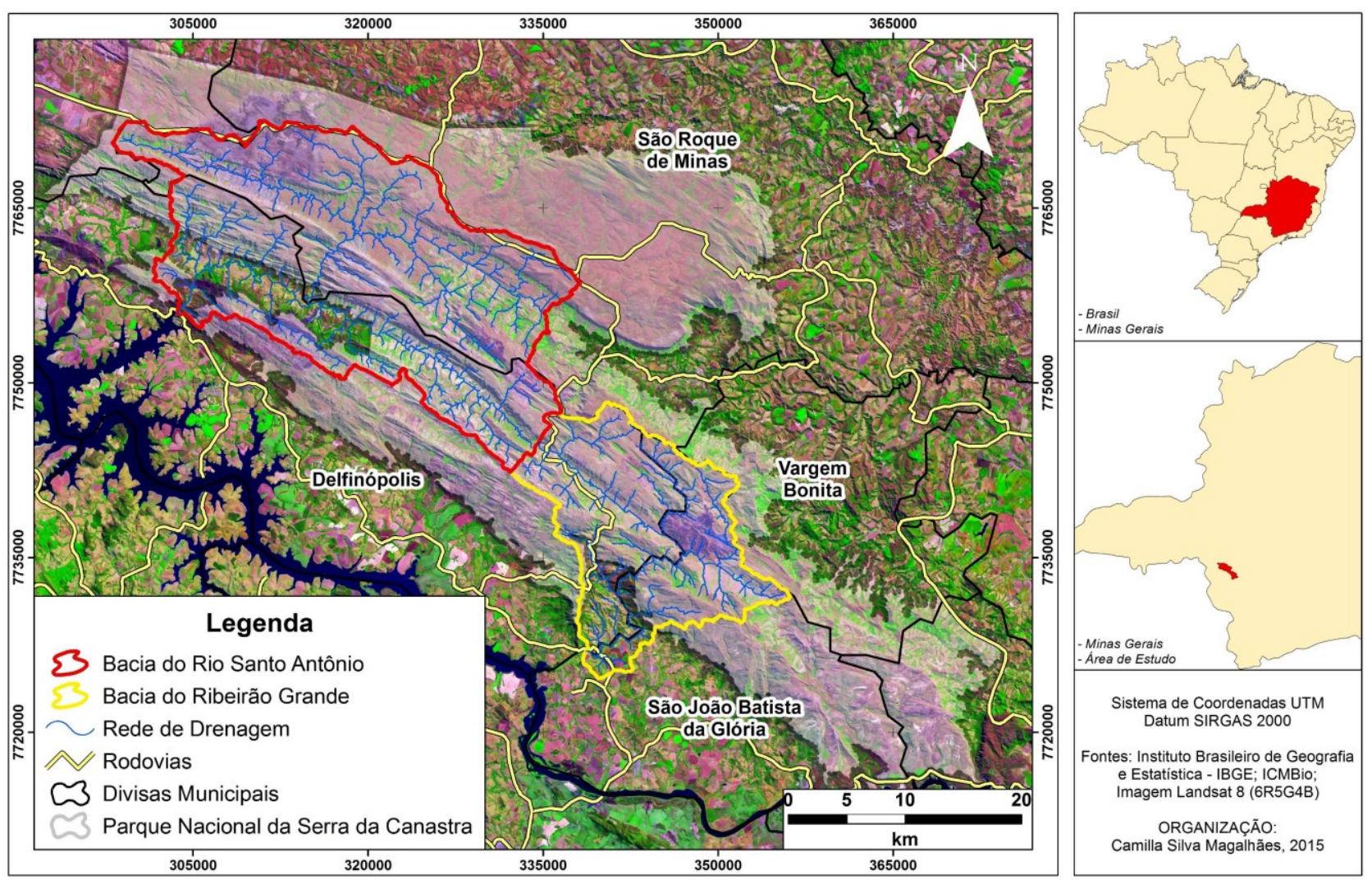

Figura 1 - Localização da área de estudo.

\section{METODOLOGIA}

Ocupando posição de destaque entre os componentes de um SIG, a base de dados se refere a coleção de mapas e informações disponíveis na forma digital, relacionadas com os elementos da superfície terrestre e geograficamente referenciadas, que subsidiará as futuras análises a serem realizadas em ambiente computacional (MIRANDA, 2010). Dessa forma, tendo em vista essa necessidade de informações espaciais, a primeira etapa do presente estudo se constituiu na aquisição e tratamento de uma base cartográfica, a qual disponibilizasse os elementos topográficos e hidrográficos da área de pesquisa em uma escala de detalhes adequada.

As bacias do Rio Santo Antônio e do Ribeirão Grande correspondem a uma área representada em sete folhas do mapeamento cartográfico brasileiro, em escala 1:50.000, são elas : Folha Chapadão da Zagaia / SF-23-V-A-III-I (IBGE, 1971ª); Folha Delfinópolis / SF-23-V-A-III-3 (IBGE, 1971b); Folha Furnas / SF-23-V-B-IV-1 (IBGE, 1971c); Folha Passos / SF-23-V-A-VI-2 (IBGE, 1971d); Folha Serra da Canastra / SF-23-V-A-III-2 (IBGE, 1971e); Folha Serra da Guarita / SF-23-V-A-III-4 (IBGE, 1971f); Folha Vargem Bonita / SF-23-V-B-I-3 (IBGE, 1970).

Visando a qualidade dos resultados a serem discutidos na pesquisa, é de suma importância a utilização de uma base cartográfica consistente tanto hidrológicamente quanto morfologicamente (FONSECA, 2010), o que torna imprescindível a correção topológica dos 40 dados a serem interpolados, caso haja alguma inconsistência. Apesar das folhas utilizadas se encontrarem em sua 
maioria vetorizadas, vários erros topológicos foram encontrados, principalmente, nos limites de articulação das cartas e em áreas de confluências da rede de drenagem. Esses erros foram corrigidos de forma semi-automática, através das ferramentas de edição vetorial e Topology do ArcGIS 10.2.2.

Um modelo é como uma abstração simplificada da realidade, a qual facilita o estudo de uma área escolhida, reduzindo o número de complexidades e de informações a serem consideradas, porém, tornando-se ao mesmo tempo uma fonte passível de potenciais distorções (MIRANDA, 2010). Partindo desse raciocínio e tendo a bacia hidrográfica como objeto de estudo, optou-se na presente pesquisa pela geração de um Modelo Digital de Terreno Hidrologicamente Consistido (MDT-HC).

Para a geração do MDT-HC foi utilizado o método de interpolação Topo to Raster, disponível em meio às ferramentas da extensão 3D Analyst, do ArcGIS 10.2.2. Esse é um método resultante da interação de diferentes técnicas de interpolação de dados, o qual visa a geração de um modelo numérico de terreno mais preciso quanto aos seus aspectos hidrológicos, sendo descrito mais detalhadamente em Esri $\left(2015^{a}, 2015 b\right)$.

Após a construção do MDT-HC foram gerados os seguintes índices morfométricos: hierarquia fluvial pelo método de Sthraler (1952), Índice de sinuosidade do canal principal (Is), Área da bacia (A), Perímetro da bacia (P), Índice de circularidade (Ke), Coeficiente de compacidade (Kc), Densidade de drenagem (Dd), Densidade de rios (Dr), Coeficiente de manutenção $(\mathrm{Cm})$, Amplitude altimétrica $(\Delta \mathrm{h})$, Declividade média, Relação de relevo $(\mathrm{Rr})$,

Importante elemento para o entendimento dos processos geomorfológicos, o perfil longitudinal consiste num método simples e eficaz, que basicamente se utiliza dos dados de altitude e extensão do canal para a geração de uma curva de ajustamento logarítmico côncavo ascendente, onde as maiores declividades são relacionadas às nascentes e as menores rumo à foz, sendo considerado a representação gráfica característica de rios em estado de equilíbrio (FUJITA, 2009).

Em aspectos gerais, a Relação Declividade-Extensão (RDE) de um curso d'água pode ser definida como "um índice que possibilita a análise de perfis longitudinais de rios e de trechos selecionados, propiciando as bases para o estabelecimento de comparações entre cursos d'água de ordem e de porte diferentes" (ETCHEBEHERE et al., 2004, p. 49). Dessa forma, seguindo a metodologia utilizada por Etchebehere et al. (2004, 2006), o índice RDE pode ser calculado da seguinte forma:

$$
R D E_{\text {total }}=\frac{\Delta h}{{ }_{\ln } L}
$$


Considerando a extensão total de um rio, onde $\Delta h$ é a diferença altimétrica entre a cota superior e inferior do canal, ou seja, a diferença entre a conta localizada a montante do rio e a cota localizada na sua foz; e $\ln L$, o logaritmo natural da extensão total do curso d'água. Ou, considerando um segmento ao longo do curso d'água:

$$
R D E_{\text {trecho }}=\frac{\Delta h}{\Delta l} * L
$$

Onde: $\Delta h$ é a diferença altimétrica entre dois pontos extremos de um segmento ao longo do curso d'água; $\Delta l$ a projeção horizontal (linha reta) da extensão do referido segmento; $\Delta h / \Delta l$ o gradiente da drenagem naquele trecho; e $L$ o comprimento total do curso d'água a montante do ponto para o qual o índice RDE está sendo calculado.

De acordo com Seeber ; Gornitz (1938 apud ETCHEBEHERE et al., 2006), serão considerados índices RDEtrecho anômalos aqueles que divididos pelo RDEtotal obtiverem valores superiores a 2. Valorização essa, que permite a categorização das anomalias em duas ordens: anomalias de $1^{\mathrm{a}}$ ordem, referentes aos valores iguais ou superiores a 10 (RDEtrecho / RDEtotal $\geq$ 10); e anomalias de $2^{\circ}$ grau, referentes aos índices compreendidos entre os limiares de 2 a $10(2 \leq$ RDEtrecho / RDEtotal $\geq 10$ ). Assim, descartadas outras possibilidades causativas de anomalias, tais limiares refletem a existência de quebras (knickpoints) ao longo do perfil longitudinal de um rio, representando pontos anômalos a ser investigados inclusive do ponto de vista neotectônico.

Os lineamentos morfoestruturais foram obtidos a partir das proposições apontadas em Andrades Filho (2010), no qual este lineamentos correspondem às expressões espaciais de feições morfológicas da paisagem que possam ter relação com feições geológicas, revelando seu comportamento tectônico, sendo em geral, expressos por: cristas de cordilheiras ou limites de áreas elevadas; linhas de drenagem; linhas de costa; e linhas representativas de contatos litológicos.

Nesse contexto, a extração dos lineamentos indiscriminados (estruturais e morfológicos) da área de estudo foi realizada por meio do logaritmo LINE: Lineament Extraction, contido no módulo Focus do software PCI/Geomatica 2012. E para a construção dos diagramas de roseta referentes às frequências e comprimentos absolutos desses lineamentos, utilizou-se do software Stereonet.

\section{RESULTADOS E DISCUSSÃO}

O reconhecimento paisagístico da área de estudo apresenta elementos associados à sua estruturação geológica e geomorfológica. De acordo com Hasui (2010), a região sudeste brasileira é caracterizada por unidades geotectônicas extremamente complexas, resultantes de cenários evolutivos cambiantes, envolvendo processos diacrônicos e com superposição. 
$\mathrm{Na}$ área de estudo, esta situação gerou a disposição atual de litologia associadas a dois períodos distintos, composto por rochas proterozóicas com pequena participação de rochas mesozoicas. (Figura 2). Dentre as rochas proterozóicas ocorrem litotipos do Grupo Canastra (BARBOSA, 1970 apud SILVA et al., 2012), procurava indicar quartzitos e filitos, em sua generalidade, localizados na região compreendida entre as serras da Canastra e da Bocaina, também ocorrem rochas do Grupo Ibiá, composto predominantemente por metapelitos e metadiamictitos. Já a Formação Araxá, é composto por micaxistos e quartzitos (BARBOSA, 1955 apud LUVIZOTTO, 2003).

Com em relação a rochas mesozoicas, ocorre de forma residual, afloramento de litologias da Formação Marília sobreposta aos quartzitos do Grupo Canastra, nos limites SW da área de estudo, em altitudes superiores a $1.250 \mathrm{~m}$, bem como também relativo a Cretáceo Inferior, a presença de evento magmático alcalino-ultrabásico, que permitiu o alojamento de dezenas de intrusões kimberlíticas, algumas delas portadoras de diamante (CHAVES et al., 2008; CHAVES, BENITEZ; ANDRADE, 2009).

\section{Mapa das Unidades Litológicas das Bacias do Rio Santo Antônio e do Ribeirão Grande}
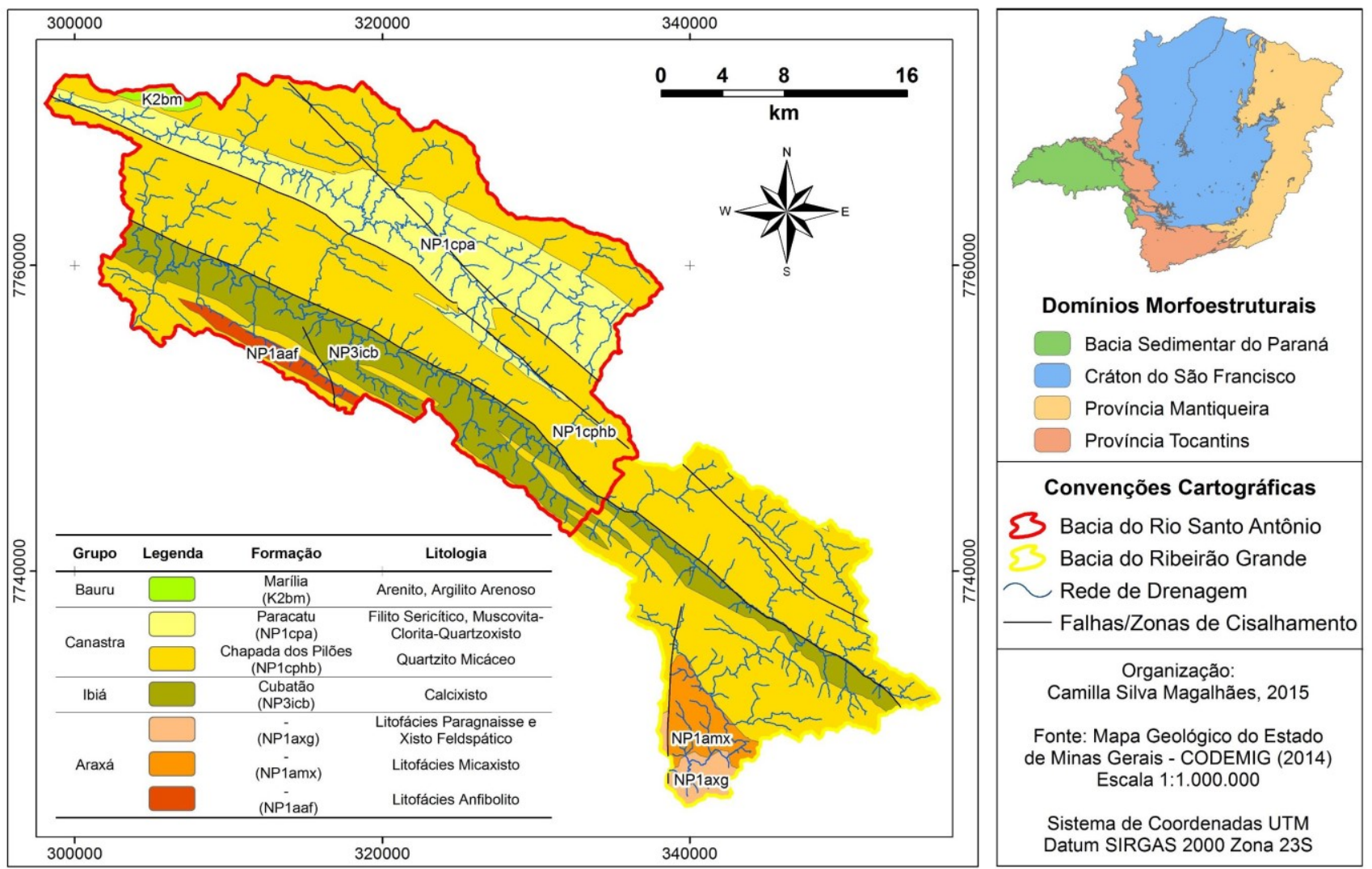

Figura 2 - Mapa das Unidades Litológicas das Bacias do Rio Santo Antônio e do Ribeirão Grande. Fonte: Magalhães, 2015. 
Apresentando íntima relação com os aspectos geológicos da região, de forma generalizada, a paisagem da área de estudo é caracterizada pela alternância de chapadas com encostas escarpadas, setores com colinas amplas e depressões intermontanas (Figura 3).

\section{Mapa dos Compartimentos de Relevo das Bacias do Rio Santo Antônio e do Ribeirão Grande}

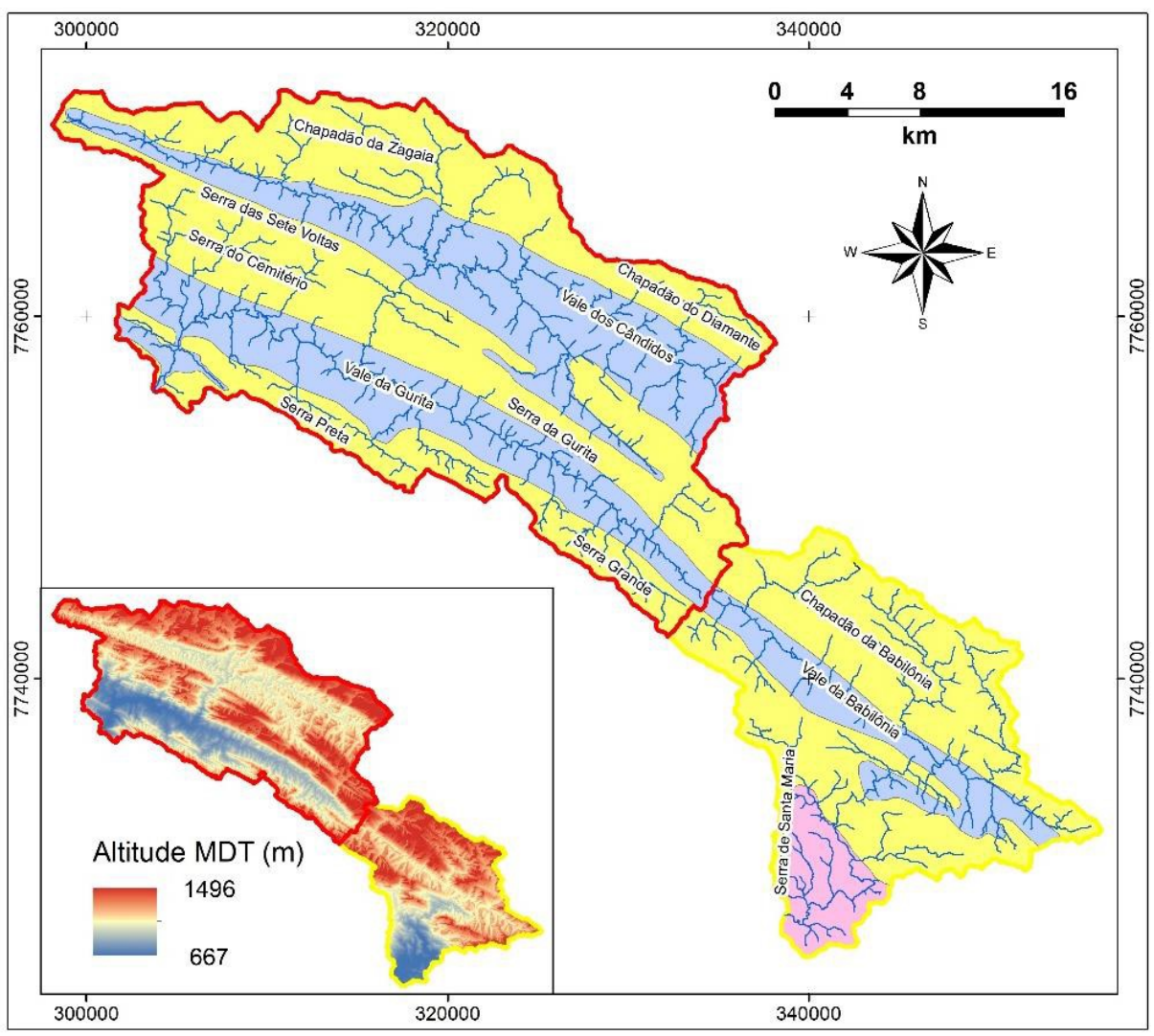

Convenções Cartográficas

E3 Bacia do Rio Santo Antônio Bacia do Ribeirão Grande

$\frown$ Rede de Drenagem

Legenda

Compartimentos de Relevo

Chapadas

Depressões Intermontanas

Colinas Amplas

Organização:

Camilla Silva Magalhães, 2015

Fonte: Mapa dos Compartimentos e Embasamento Físico da Paisagem do PNSC e Entorno Imediato MMA/IBAMA (2005) Escala 1:500.000

Sistema de Coordenadas UTM Datum SIRGAS 2000 Zona 23S

Figura 3 - Mapa dos Compartimentos de Relevo das Bacias do Rio Santo Antônio e do Ribeirão Grande.

Fonte: Magalhães, 2015.

A fim de se contrapor os valores encontrados em diferentes escalas de observação, a análise morfométrica foi aplicada às duas bacias estudadas em sua totalidade e às suas sub-bacias de quarta ordem, nível hierárquico escolhido pela consistência da delimitação extraída automaticamente através do MDT-HC e por apresentar um número constante em ambas as bacias principais. Dessa forma, a Tabela 1 traz uma síntese dos índices morfométricos que foram analisados nesse primeiro momento:

Conforme é possível observar na Figura 4, as bacias hidrográficas aqui analisadas possuem seus eixos principais de drenagem dispostos paralelamente, seguindo a orientação NW-SE associados a estruturação de suas unidades litológicas, enquanto grande parte dos canais de ordens inferiores se posicionam de forma ortogonal, tendo como direção os alinhamentos coincidentes às juntas de sentido NE-SW, corroborando os estudos de Souza e Rodrigues (2014) e Nazar e Rodrigues (2019 a e b). 
Tabela 1 - Índices morfométricos encontrados para as bacias do Rio Santo Antônio e do Ribeirão grande em sua totalidade.

\begin{tabular}{|c|c|c|}
\hline \multirow{2}{*}{ ÍNDICES MORFOMÉTRICOS } & \multicolumn{2}{|c|}{ BACIA } \\
\hline & RIO STO. ANTÔNIO & RIBEIRÃO GRANDE \\
\hline Hierarquia Fluvial (Strahler) & 6 & 6 \\
\hline Número de Canais ( $1^{\mathrm{a}}$ Ordem $)$ & 1317 & 615 \\
\hline Comprimento Total dos Canais $(\mathrm{km})$ & 1374,20 & 657,78 \\
\hline Comprimento do Canal Principal (km) & 57,37 & 50,79 \\
\hline Índice de Sinuosidade (Is) & 1,66 & 2,23 \\
\hline Área da Bacia $\left(\mathrm{km}^{2}\right)$ & 610,52 & 278,62 \\
\hline Perímetro $(\mathrm{km})$ & 141,52 & 91,20 \\
\hline Índice de Circularidade (Ke) & 0,38 & 0,42 \\
\hline Coeficiente de Compacidade (Kc) & 1,60 & 1,53 \\
\hline Densidade de Drenagem $\left(\mathrm{km} / \mathrm{km}^{2}\right)$ & 2,25 & 2,36 \\
\hline Densidade de Rios (canais $/ \mathrm{km}^{2}$ ) & 2,16 & 2,20 \\
\hline Coeficiente de Manutenção (m) & 444,27 & 423,58 \\
\hline Altitude Máxima (m) & 1496,48 & 1469,71 \\
\hline Altitude Média (m) & 1111,74 & 1125,31 \\
\hline Altitude Mínima (m) & 672,75 & 671,68 \\
\hline Amplitude Altimétrica (m) & 823,72 & 798,02 \\
\hline Declividade Média (\%) & 24,29 & 22,61 \\
\hline Índice de Rugosidade (Ir) & 54,65 & 53,35 \\
\hline Relação de Relevo (m/km) & 14,36 & 15,71 \\
\hline
\end{tabular}

Fonte: Magalhães, 2015.

Seguindo a hierarquização proposta por Strahler, ambas as bacias apresentam drenagens classificadas como de até sexta ordem, possuindo a Bacia do Rio Santo Antônio 1317 canais de primeira ordem e a Bacia do Ribeirão Grande 615 canais de ordem equivalente. Este número é considerado importante, uma vez que, ele corresponde ao número total de rios existentes em cada bacia.

Analisando as distâncias percorridas pelo fluxo de água superficial entre os divisores topográficos até a sua foz (Figura 5), ambas as bacias apresentam canais principais com comprimento entre 50 e $60 \mathrm{~km}$, o que faz a Bacia do Ribeirão Grande apresentar um índice de sinuosidade maior, devido à sua área ser inferior à metade da outra bacia estudada . 


\section{Mapa de Hierarquia Fluvial das Bacias do Rio Santo Antônio e do Ribeirão Grande}

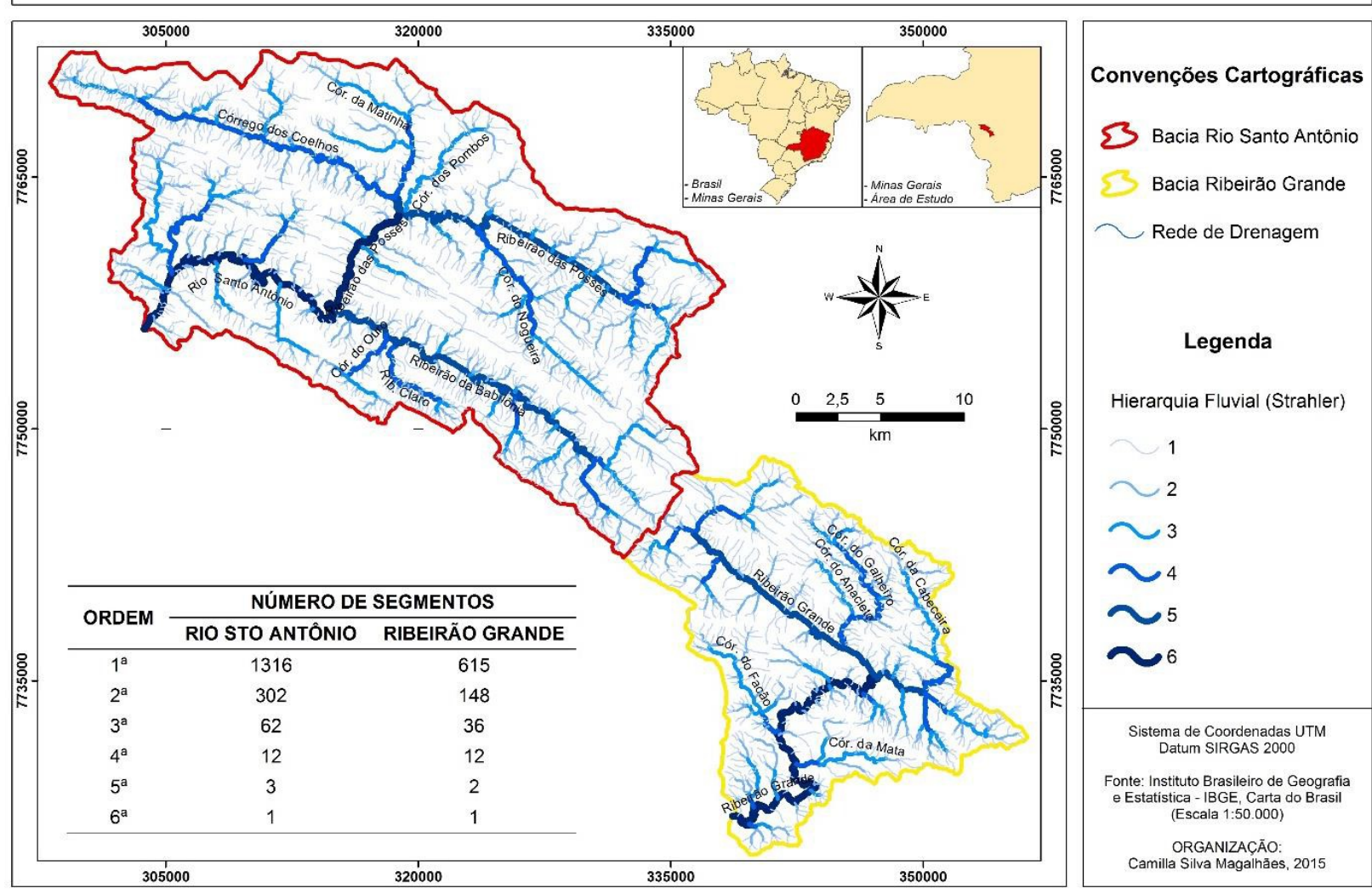

Figura 4 - Hierarquia fluvial das bacias do Rio Santo Antônio e Ribeirão Grande.

Fonte: Magalhães, 2015.

Assim, tendo em vista que este índice busca conhecer a divagação de um curso d'água e, consequentemente, a velocidade do seu fluxo associada ao transporte e deposição de sedimentos, no caso da Bacia do Ribeirão Grande, constata-se que mesmo possuindo fluxo mais lento, as drenagens localizadas em suas áreas de planície são caracterizadas por uma certa retilineidade e ausência de meandros bem desenvolvidos, sendo sua sinuosidade derivada dos controles estruturais sobre a rede de drenagem, principalmente em sua porção centro-sul.

Em seus aspectos areais, a Bacia do Rio Santo Antônio possui um território com 610,52 km2 e perímetro de aproximadamente $141 \mathrm{~km}$, enquanto a Bacia do Ribeirão Grande perfaz uma área de apenas $278,62 \mathrm{~km}^{2}$, com perímetro próximo a $91 \mathrm{~km}$. Sendo estes, atributos fundamentais na análise de suas formas.

Dentre os vários índices utilizados na determinação da forma de uma bacia, o índice de circularidade é um dos que recebe maior destaque, buscando elucidar como se dá o tempo de concentração das águas no seu interior, através da relação entre a sua área e a área de um círculo que possua perímetro idêntico ao seu. Neste cenário, com índices de circularidade inferiores ao limiar médio de 0,51, ambas as bacias apresentam forma semi-alongada, o que favorece relativamente o escoamento das águas pluviais e diminui a probabilidade de cheias. 


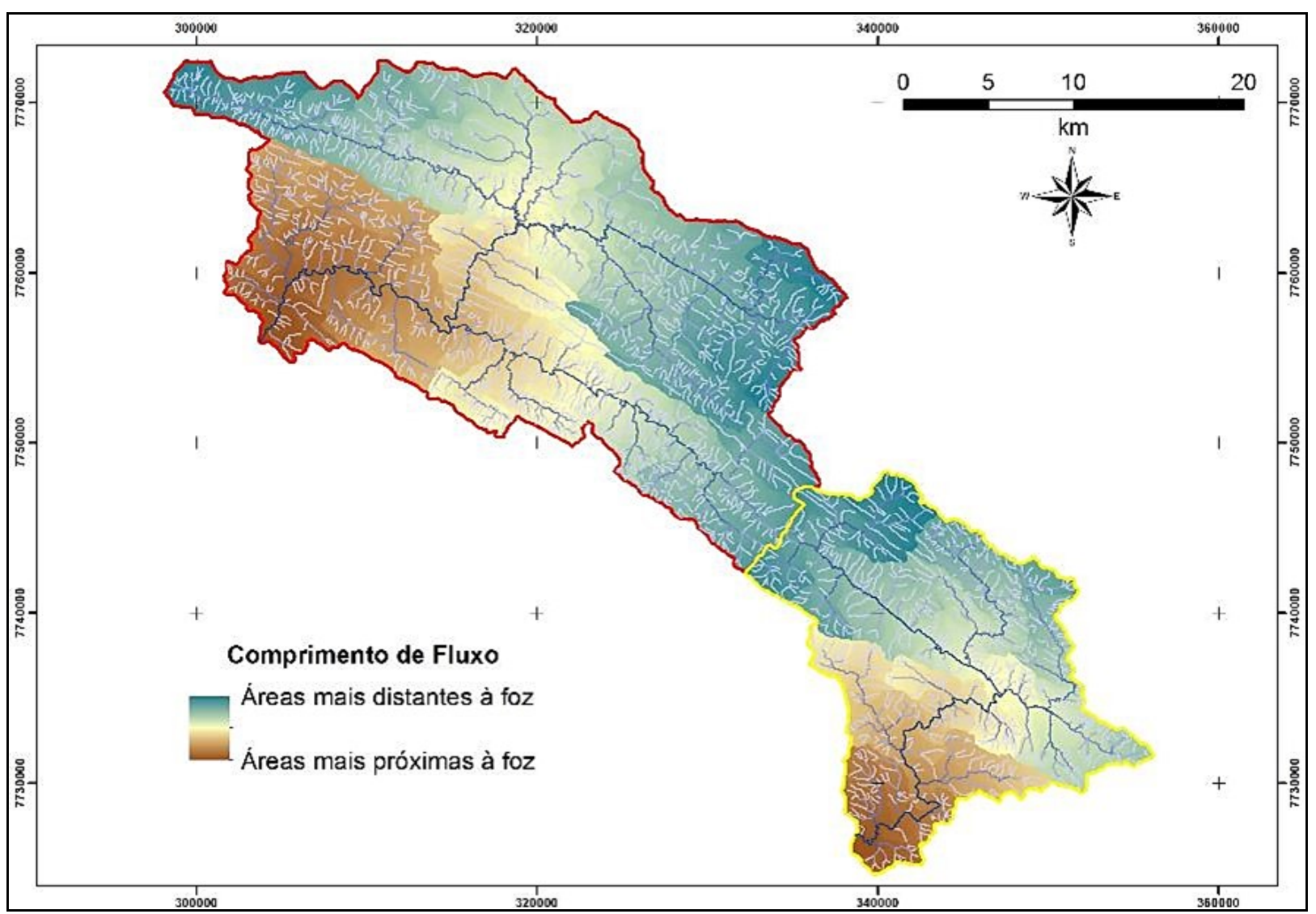

Figura 5 - Representação dos comprimentos de fluxos nas bacias estudadas.

Fonte: Magalhães (2015).

Fato constatado também, através do coeficiente de compacidade, que é a relação do perímetro da bacia e a circunferência de um círculo de área igual a sua, onde valores próximos a 1 caracterizam bacias de forma circular e valores superiores, como no caso de 1,53 e 1,60, bacias com tendências de formas mais alongadas.

Voltando-se para os parâmetros que relacionam a composição da rede drenagem à área da bacia, foram calculados para a presente pesquisa a densidade de rios, a densidade de drenagem e o coeficiente de manutenção. Sucintamente, a primeira corresponde à relação entre o número de rios e a área da bacia; a segunda à relação entre o comprimento total dos cursos d'água e a área de drenagem; e o terceiro à área necessária para a formação de um canal.

Neste contexto, observa-se que, em sua totalidade, a área de estudo apresenta uma densidade média de 2,18 canais por $\mathrm{km}^{2}$, ou seja, uma densidade de rios relativamente alta (Figura 6), a qual influência diretamente na sua densidade de drenagem, composta predominantemente por canais de comprimento inferior a $1 \mathrm{~km}$ de extensão. Configuração hidrológica está condicionada pela litologia e estrutura geológica da região, onde a presença de terrenos menos friáveis auxilia na formação de novos canais superficiais, que segundo o coeficiente de manutenção necessitam de área aproximada a $434 \mathrm{~m}^{2}$ para se manterem perenes. 


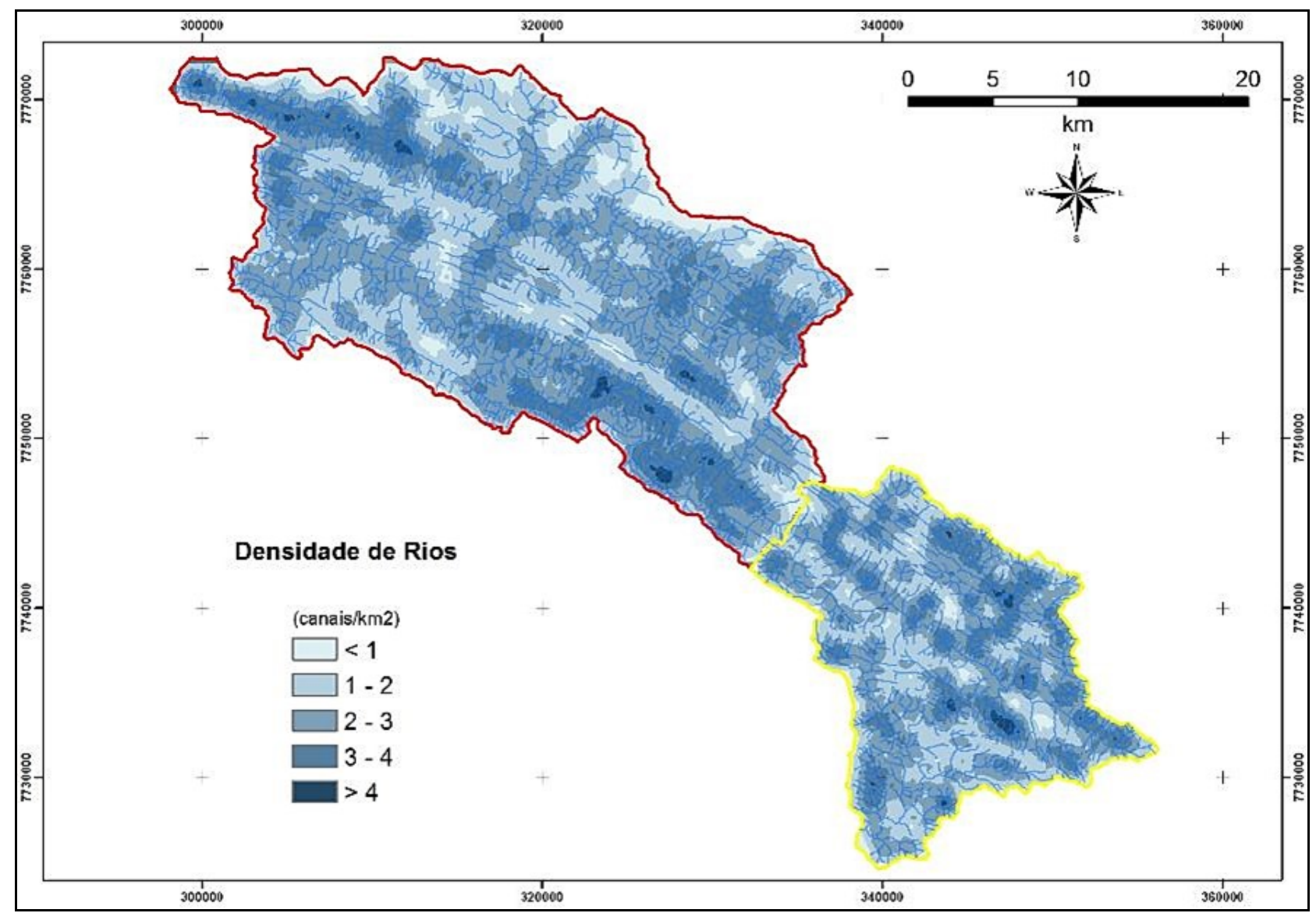

Figura 6 - Densidade de rios para a área de estudo em sua totalidade.

Fonte: Magalhães, 2015.

Em seus aspectos hipsométricos, as bacias apresentam amplitude altimétrica variando entre 798 e 823 m, sendo as maiores altitudes localizadas na porção norte da Bacia do Rio Santo Antônio (1496 m), na área de abrangência do Chapadão da Canastra, e, as altitudes mais baixas (671 m), próximas a foz do Ribeirão Grande (Figura 7).

Ao se calcular o índice de rugosidade, tem-se como objetivo relacionar as qualidades de declividade e comprimento das vertentes, com a densidade de drenagem. Assim, se uma área apresenta vertentes longas e íngremes, os valores da rugosidade do relevo serão elevados, como no caso da área de estudo, que variam entre 53,35 e 54,65, influenciadas pela presença de serras fortemente escarpadas (Figura 8).

Contudo, de forma complementar, a aplicação do índice de relação do relevo, traz uma variável considerando a razão entre a amplitude altimétrica e o comprimento do canal principal da bacia, apresentando como resultado uma relação de variação altimétrica a cada quilômetro de extensão do curso d'água. Por exemplo, numa sequência linear, a cada quilômetro percorrido pelo Rio Santo Antônio, sua altimetria acresce ou diminuiu (variando o sentido do fluxo) 14,36 m, enquanto o Ribeirão Grande varia em 15,71 m. 


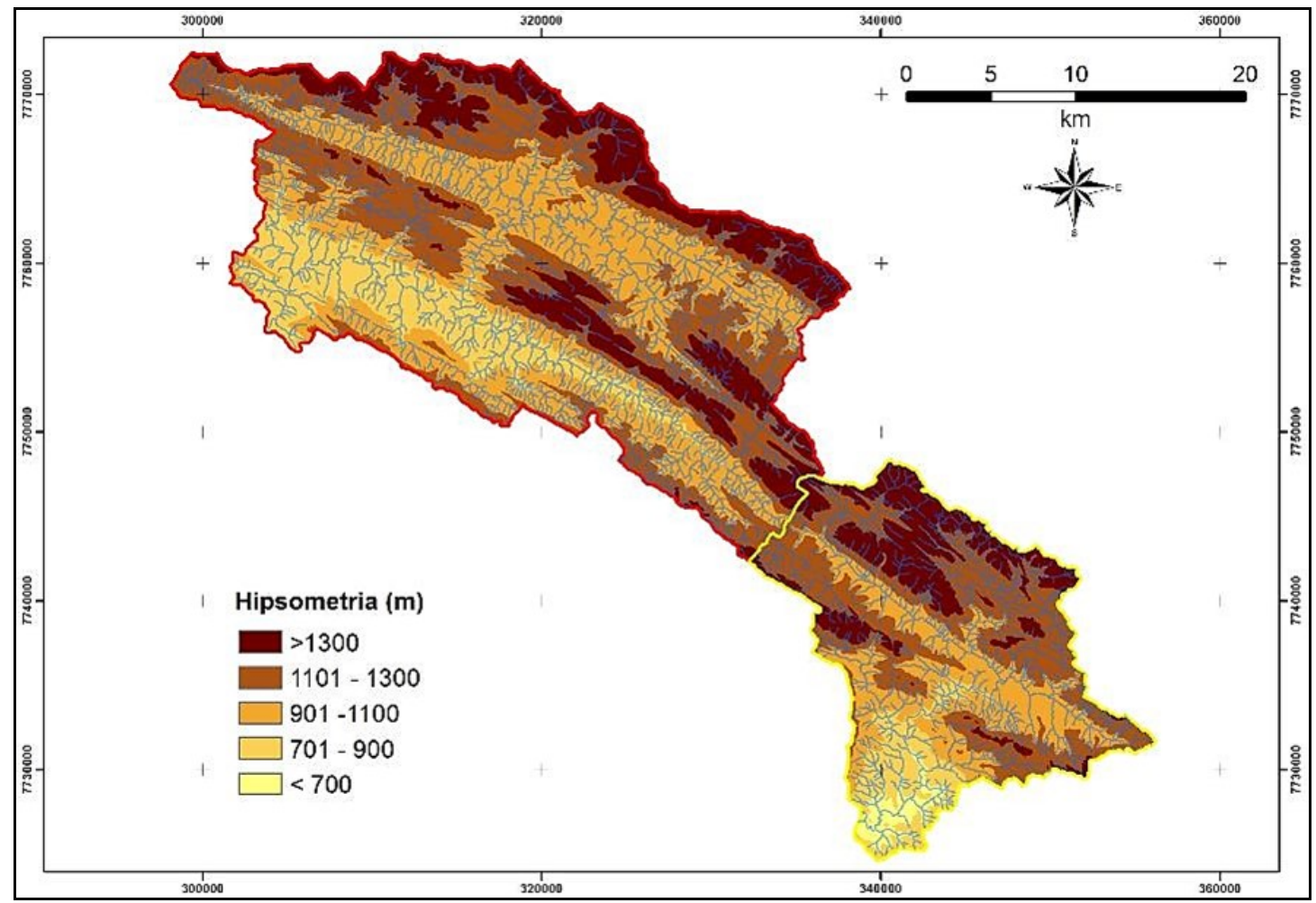

Figura 7 - Variação hipsométrica nas bacias do Rio Santo Antônio e do Ribeirão Grande. Fonte: Magalhães, 2015.

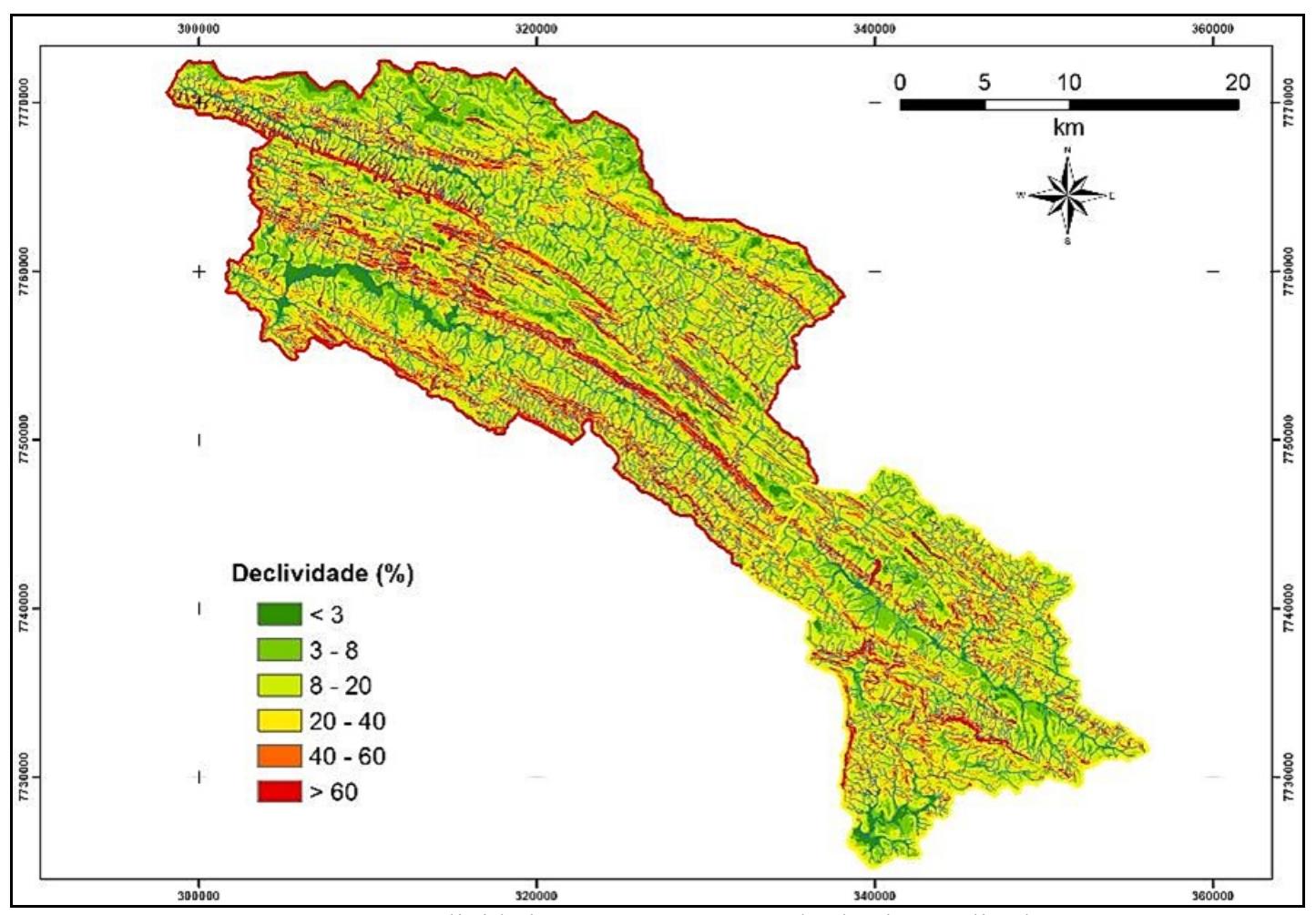

Figura 8 - Declividade, em porcentagem, das bacias analisadas. Fonte: Magalhães, 2015. 
A fim de se verificar uma possível influência dos aspectos hipsométricos e de declividade sobre os canais de drenagem segundo à sua ordenação hierárquica, foi realizado o cálculo do gradiente de canais (declividade) e do índice de sinuosidade para cada segmento de drenagem, cujo resultado consiste na Figura 9:

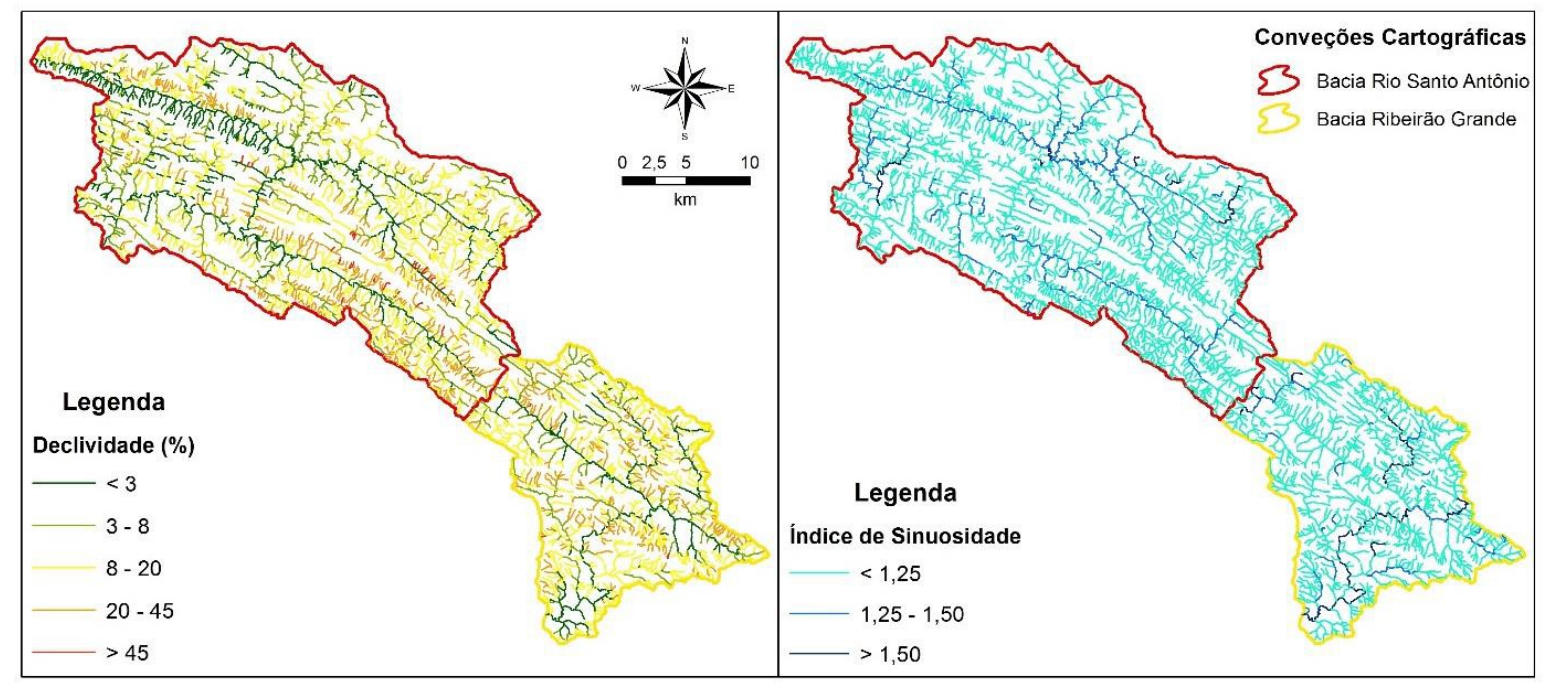

Figura 9 - Espacialização da declividade e do índice de sinuosidade para os canais de drenagem.

Fonte: Magalhães (2015).

Logo, observa-se que (com exceção dos tributários da margem direita do Córrego dos Coelhos, porção NW da Bacia do Rio Santo Antônio, cujas baixas declividades estão associadas a erros na determinação da amplitude altimétrica desses segmentos) os canais de ordens superiores e situados nas áreas de vales, com uma tendência a maior estabilidade, são aqueles que possuem menores declives. Enquanto que os canais de ordens inferiores, muitas vezes associados às áreas de escarpas ou maior dissecação do relevo, apresentam gradientes mais elevados.

Ao criar o índice SL (Stream-Gradient index), Hack (1973) tinha por objetivo estabelecer um parâmetro fluviomorfométrico para analisar os perfis longitudinais dos cursos d'água, ou de determinado trecho desses. Assim, ao correlacionar a declividade de um segmento de drenagem com a sua extensão, ele buscou relacionar os níveis de energia da corrente, refletida na capacidade de esta erodir o substrato e/ou transportar carga sedimentar (ETCHEBEHERE et al., 2006).

Como já mencionado, o perfil longitudinal de um rio em estado de equilíbrio é caracterizado por uma concavidade para o céu, com declives maiores próximos à nascente e mais suaves em direção à sua foz. Entretanto, ao longo do seu curso, é comum a ocorrência de trechos em diferentes níveis de equilíbrio e desequilíbrio, funcionando o índice RDE como indicador sensível às mudanças na declividade do canal fluvial (CHRISTOFOLLETI, 1980; ETCHEBEHERE et al., 2006). 
Dessa forma, em um primeiro momento, foi calculado o RDEtotal para todos os canais de extensão superior a $3 \mathrm{~km}$ encontrados em ambas bacias, totalizando-se 48 canais na Bacia do Rio Santo Antônio e 25 na Bacia do Ribeirão Grande. Determinado o índice para cada um, esse foi plotado no ponto médio de cada canal analisado, conforme Etchebehere et al. (2004, 2006), possibilitando a sua espacialização e avaliação em caráter regional. Em conformidade com a Figura 10, observa-se que os valores de RDEtotal tendem a ser mais elevados nas regiões onde os quartzitos micáceos do Grupo Canastra se encontram mais dissecados e nas áreas dos médios cursos (800-100 m) dos canais principais das bacias analisadas, onde esses apresentam forte controle estrutural e maior vigor energético.

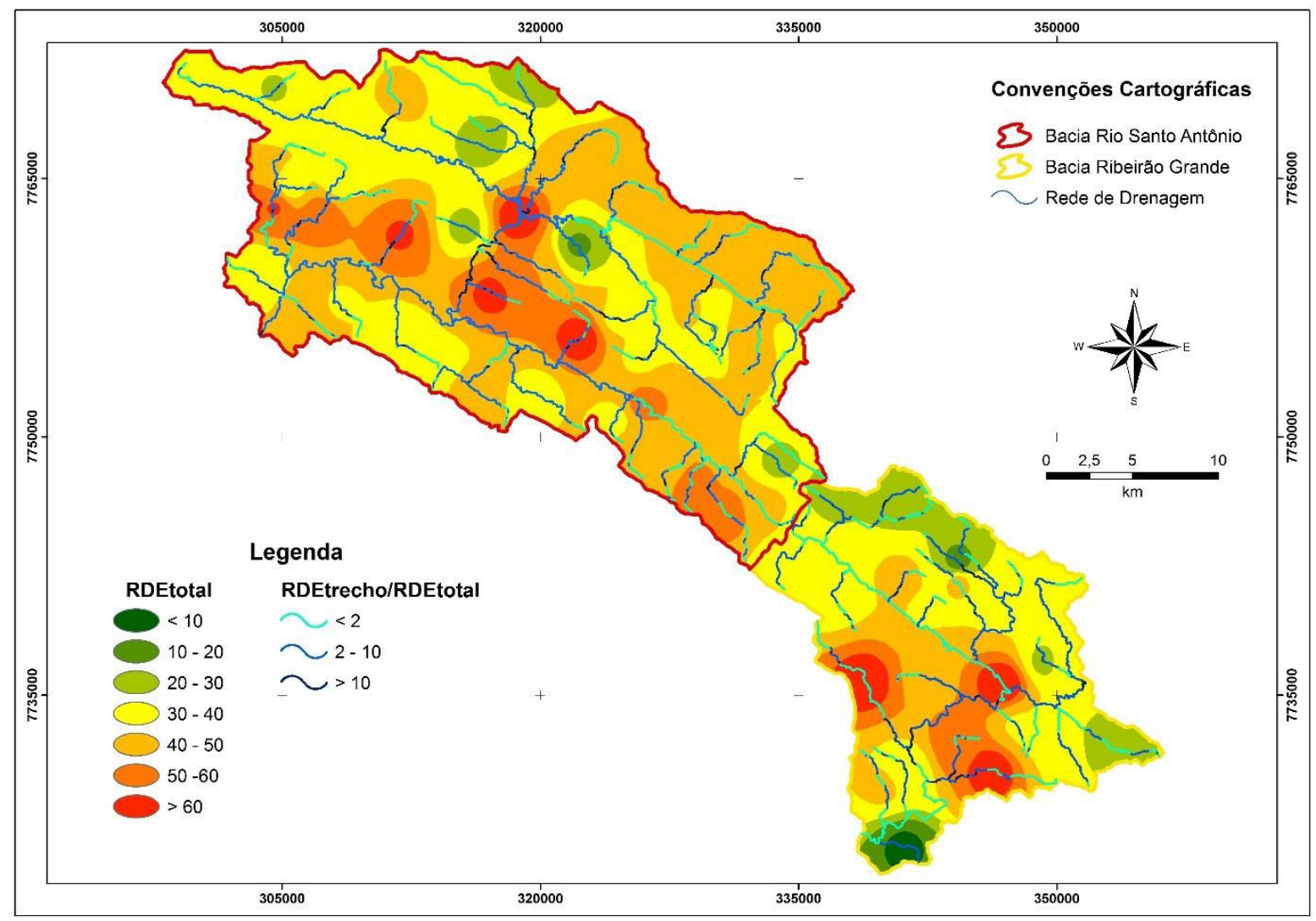

Figura 10 - Distribuição do RDEtotal pela área de estudo.

Fonte: Magalhães (2015).

Por sua vez, para o cálculo dos valores equivalentes aos RDEtrecho, utilizou-se os mesmos canais anteriores, os quais foram segmentados segundo as curvas de nível extraídas das cartas do IBGE, de equidistância igual a $20 \mathrm{~m}$, buscando identificar a ocorrência de anomalias pontuais.

\section{CONSIDERAÇÕES FINAIS}

A partir da análise morfométrica das bacias em sua totalidade, mesmo elas apresentando áreas desproporcionais uma com a outra, em aspecto geral, suas respostas foram semelhantes aos parâmetros calculados. Todavia, ao dividi-las em unidades menores, observou-se que a 
morfodinâmica de suas partes, pode não corresponder à sua tendência geral, ocasionando morfologias e processos morfogenéticos distintos pela sua extensão, condicionados por aspectos geológicos e hipsométricos.

Por meio do exame dos perfis longitudinais dos seus canais principais, constatou-se que ao contrário do que se imaginava no início da pesquisa, essas bacias não apresentam dinâmicas energéticas semelhantes, tendo o Rio Santo Antônio maior potência. Fato que pode ser justificado, por exemplo, pelos diferentes níveis de dissecação que ocorrem sobre os platôs quartzíticos, de forma que o Chapadão do Diamante imprime sobre a curva inicial do RSA uma feição convexa e o Chapadão da Babilônia sobre o RG uma feição predominantemente côncava.

O índice RDE serviu para reforçar o papel que as morfoestruturas exercem sobre as redes de drenagem, uma vez que todas as anomalias encontradas nos canais principais, puderam ser relacionadas aos aspectos geotectônicos da área, em grande parte representados por rupturas de declive, na forma de cachoeiras e corredeiras, ou por trechos de baixa potência e alta sinuosidade, em litologias menos resistentes.

Por fim, é importante se destacar que a qualidade dos resultados obtidos está diretamente relacionada à opção de se utilizar um MDT-HC, com resolução espacial de $10 \mathrm{~m}$, o qual possibilitou uma modelagem de maior detalhe e mais confiável frente às feições morfológicas e aos fluxos hidrológicos do terreno da área de estudo. Etapa que nos remete, a significância que os Sistemas de Informações Geográficas alcançam frente às análises ambientais, possibilitando: a aquisição, o armazenamento, a manipulação, a interpretação e a apresentação de dados espaciais, com maior rapidez, consistência, precisão e uniformidade nos procedimentos operacionais.

\section{AGRADECIMENTOS}

O presente trabalho foi realizado com apoio da FAPEMIG concedido através do projeto CRA APQ-0231/2016. Agradecemos pelo apoio do ICMBio na execução do projeto no interior do ParnaCanastra.

\section{REFERÊNCIAS}

ANDRADES FILHO, C. O. Análise morfoestrutural da porção central da Bacia do Paraíba (PB) a partir de dados MDE-SRTM e ALOS-PALSAR FDB. 2010. 177 f. Dissertação (Mestrado em Sensoriamento Remoto), Instituto Nacional de Pesquisas Espaciais, São José dos Campos, 2010.

CHAVES, M. L. S. C.; ANDRADE, K. W.; BENITEZ, L.; BRANDÃO, P. R. G. Província Diamantífera da Serra da Canastra e o Kimberlito Canastra-1: primeira fonte primária de diamantes economicamente viável do país. Geociências, v. 27, n. 3, p. 299-317, 2008. 
CHAVES, M. L. S. C.; BENITEZ, L.; ANDRADE, K. W. Cachoeira da Casca D'Anta, São Roque de Minas, MG: berço do Velho Chico, o rio da integração nacional. In: WINGE, M.; SCHOBBENHAUS, C.; SOUZA, C. R. G.; FERNANDES, A. C. S.; QUEIROZ, E. T.; BERBERT-BORN, M.; CAMPOS, D. A. (Edts). Sítios geológicos e paleontológicos do Brasil. Brasília: CPRM, 2009. p. 151-162.

CHRISTOFOLETTI, A. Geomorfologia. 2. ed. São Paulo: Blucher, 1980. 188p.

CHRISTOFOLETTI, A. Modelagem de sistemas ambientais. São Paulo: Blucher, 1999. 236p.

COUTO, E. V. Influência morfotectônica e morfoestrutural na evolução das drenagens nas bordas planálticas do Alto Ivaí - Rio Alonzo - Sul do Brasil. 2011. 120 f. Dissertação (Mestrado em Geografia) - Centro de Ciências Humanas Letras e Artes, Universidade Estadual de Maringá, Maringá, 2011.

ESRI. Hydrologically correct surfaces: Topo to Raster in 3D Analyst. Disponível em: $<$ http://resources.esri.com/help/9.3/arcgisengine/java/gp_toolref/geoprocessing_with_3d_analyst/hydrol ogically_correct_surfaces_colon_topo_to_raster_in_3d_analyst.htm $>$. Acesso em: 01 jan. 2015a.

ESRI. How Topo to Raster works. Disponível em: <http://resources.arcgis.com/en/help/main /10.1/index.html\#//009z0000007m000000>. Acesso em: 01 jan. 2015b.

ETCHEBEHERE, M. L. C.; SAAD, A. R.; FulfarO, V. J.; PERINOTTO, J. A. J. Aplicação do índice "relação declividade-extensão - RDE" na Bacia do Rio do Peixe (SP) para a detecção de deformações neotectônicas. Revista do Instituto de Geociência, São Paulo, v. 4, n. 2, p. 43-56, 2004.

ETCHEBEHERE, M. L. C.; SAAD, A. R.; SANTONI, G.; CASADO, F. C.; FULFARO, V. J. Detecção de prováveis deformações neotectônicas no Vale do Rio do Peixe, Região Ocidental Paulista, mediante aplicação de índices RDE (Relação Declividade-Extensão) em segmentos de drenagem. Geociências, São Paulo, v. 25, n. 3, p. 271-287, 2006.

FONSECA, B. M. O uso do sistema de informações geográficas na análise morfométrica e morfológica de bacias de drenagem na Serra do Espinhaço Meridional - MG. 2010. 100 f. Dissertação (Mestrado em Geografia) - Departamento de Geografia, Universidade Federal de Minas Gerais, Belo Horizonte, 2010.

FUJITA, R. H. O perfil longitudinal do Rio Ivaí e sua relação com a dinâmica de fluxos. 2009. 118 f. Dissertação (Mestrado em Geografia) - Centro de Ciências Humanas, Letras e Artes, Universidade Estadual de Maringá, Maringá, 2009.

HACK, J. T. Stream-profile analysis and stream-gradient index. Journal of Research of the U. S. Geological Survey, v. 1, n. 4, p. 421-429, 1973.

HASUI, Y. A grande colisão pré-cambriana do sudeste brasileiro e a estruturação regional. Geociências, São Paulo, v. 29, n. 2, p. 141-169, 2010.

IBGE. Departamento Geográfico do Estado de Minas Gerais. Vargem Bonita. Rio de Janeiro: IBGE, 1970. Escala 1:50.000.

IBGE. Departamento Geográfico do Estado de Minas Gerais. Chapadão da Zagaia. Rio de Janeiro: IBGE, 1971a. Escala 1:50.000.

IBGE. Departamento Geográfico do Estado de Minas Gerais. Delfinópolis. Rio de Janeiro: IBGE, 1971b. Escala 1:50.000.

IBGE. Departamento Geográfico do Estado de Minas Gerais. Furnas. Rio de Janeiro: IBGE, 1971c. Escala 1:50.000. 
IBGE. Departamento Geográfico do Estado de Minas Gerais. Passos. Rio de Janeiro: IBGE, 1971d. Escala 1:50.000.

IBGE. Departamento Geográfico do Estado de Minas Gerais. Serra da Canastra. Rio de Janeiro: IBGE, 1971e. Escala 1:50.000.

IBGE. Departamento Geográfico do Estado de Minas Gerais. Serra da Guarita. Rio de Janeiro: IBGE, 1971f. Escala 1:50.000. 109

LUVIZOTTO, G. L. Caracterização metamórfica das rochas do Grupo Araxá na região de São Sebastião do Paraíso, sudoeste de Minas Gerais. 2003. 171 f. Dissertação (Mestrado em Geociência) - Instituto de Geociência e Ciências Exatas, Universidade Estadual Paulista, Rio Claro, 2003.

MAGAlHÃES, C. S. A Aplicação de Parâmetros Morfométricos no Estudo do Relevo das Bacias do Rio Santo Antonio e Ribeirão Grande, Sudoeste de Minas Gerais. 2015. 112p. Dissertação (Mestrado em Geografia) - Programa de Pós-Graduação em Geografia - Universidade Federal de Uberlândia. Uberlândia, 2015.

MATIAS, L. F. Sistema de Informações Geográficas (SIG): teoria e métodos para representação do espaço geográfico. 2001. 325 f. Tese (Doutorado em Geografia Humana) - Departamento de Geografia da Faculdade de Filosofia, Letras e Ciências Humanas, Universidade de São Paulo, São Paulo, 2001.

MIRANDA, J. I. Fundamentos de Sistemas de Informações Geográficas. 2. ed. Brasília: Embrapa Informação Tecnológica, 2010. 425p.

NAZAR, T. I. S. M.; RODRIGUES, S. C. Relevo do Chapadão do Diamante, Serra da Canastra/MG, Brasil: compartimentação e análise a partir dos aspectos geomorfométricos. Revista Brasileira de Geomorfologia, v. 20, p. 69-88, 2019a. http://dx.doi.org/10.20502/rbg.v20i1.1300

NAZAR, T. I. S. M.; RODRIGUES, S. C. Mapeamento e Análise de Geocoberturas no Chapadão do Diamante - MG - Brasil. Mercator, Fortaleza, v. 18, p. 1-19, $2019 \mathrm{~b}$. http://dx.doi.org/10.4215/rm2019.e18010.

SILVA, C. H.; SIMÕES, L. S. A.; DAMÁZIO, W. L.; FERREIRA, S. N.; LUVIZOTTO, G. L. O Grupo Canastra em sua área-tipo, região de Tapira, sudoeste do estado de Minas Gerais, Revista do Instituto de Geociências, São Paulo, v. 12, n. 2, p. 83-98, 2012. https://doi.org/10.5327/Z1519$\underline{874 X 2012000200006}$

SOUZA, D. A.; RODRIGUES, S. C. Aspectos Morfoestruturais da Serra da Canastra e entorno (MG). Revista do Departamento de Geografia - USP, São Paulo, v. 27, p. 47-66, 2014. https://doi.org/10.11606/rdg.v27i0.472

STRAHLER, A. N. Hipsometric (area-altitude) analysis and erosional topography. Geological Society of America Bulletin, v. 63, n. 10, p. 1117-1142, 1952.

Trabalho enviado em 21/10/2019

Trabalho aceito em 01/12/2019 